\title{
The role of skin conductance level reactivity in the impact of children's exposure to interparental conflict on their attention performance
}

\author{
Zemp, Martina ; Bodenmann, Guy ; Cummings, E Mark
}

\begin{abstract}
Previous research suggests that undermining of attention performance might be one decisive underlying mechanism in the link between marital conflict and children's academic maladjustment, but little is known about specific risk patterns in this regard. This study examines, in an experimental approach, the role of children's history of interparental discord and skin conductance level reactivity (SCLR) as moderators in the link between analogue marital conflict exposure and children's attention. The attention performance of 57 children, aged 11 to 13 years, was assessed prior to and immediately after a 1-min video exposure to either (a) a couple conflict or (b) a neutral condition. SCLR was measured continuously throughout the stimulus presentation. Results indicated that children's family background of interparental conflict and their physiological reactivity moderated the influence of the experimental stimulus on children's short-term attention performance. Lower SCLR served as a protective factor in children from high-conflict homes exposed to the couple conflict. The current study advances the body of knowledge in this field by identifying risk patterns for the development of attention problems in children in relation to marital conflict exposure.
\end{abstract}

DOI: https://doi.org/10.1016/j.jecp.2013.09.007

Posted at the Zurich Open Repository and Archive, University of Zurich

ZORA URL: https://doi.org/10.5167/uzh-85968

Journal Article

Accepted Version

Originally published at:

Zemp, Martina; Bodenmann, Guy; Cummings, E Mark (2014). The role of skin conductance level reactivity in the impact of children's exposure to interparental conflict on their attention performance. Journal of Experimental Child Psychology, 118:1-12.

DOI: https://doi.org/10.1016/j.jecp.2013.09.007 
Journal of Experimental Child Psychology, in press

The role of skin conductance level reactivity in the impact of children's exposure to interparental conflict on their attention performance

Martina Zemp ${ }^{\mathrm{a}}$, Guy Bodenmann ${ }^{\mathrm{b}}$, and E. Mark Cummings ${ }^{\mathrm{c}}$

${ }^{\text {a}}$ Please address correspondence to Martina Zemp, University of Zurich, Department of Psychology, Binzmuehlestrasse 14/23, 8050 Zurich, Switzerland;

Email: martina.zemp@psychologie.uzh.ch, Phone number: +41 446357388.

${ }^{\mathrm{b}}$ University of Zurich, Department of Psychology, Binzmuehlestrasse 14/23, 8050 Zurich, Switzerland; Email: guy.bodenmann@psychologie.uzh.ch.

${ }^{\mathrm{c}}$ University of Notre Dame, Department of Psychology, 215 Haggar Hall, Indiana 46556, USA; Email: ecumming@nd.edu. 
INTERPARENTAL CONFLICT, SCLR, AND CHILD'S ATTENTION

Abstract

Objective: Previous research suggests that undermining of attention performance might be one decisive underlying mechanism in the link between marital conflict and children's academic maladjustment but little is known about specific risk patterns in this regard. This study examines in an experimental approach the role of child's history of interparental discord and skin conductance level reactivity (SCLR) as moderators in the link between analogue marital conflict exposure and child's attention. Method: Attention performance of fifty-seven children, aged 11 - 13 years, was assessed prior to and immediately after a 1-min video exposure to either (1) a couple conflict or (2) a neutral condition. SCLR was measured continuously throughout the stimulus presentation. Results: Results indicated that the children's family background of interparental conflict and their physiological reactivity moderated the influence of the experimental stimulus on child's shortterm attention performance. Lower SCLR served as protective factor in children from highconflict homes exposed to the couple conflict. Conclusion: The current study advances the body of knowledge in this field by identifying risk patterns for the development of attention problems in children in relation to marital conflict exposure.

Keywords: marital conflict; electrodermal activity; physiological reactivity; attention problems; emotional security; sensitization hypothesis 
INTERPARENTAL CONFLICT, SCLR, AND CHILD'S ATTENTION

The role of skin conductance level reactivity in the impact of children's exposure to interparental conflict on their attention performance

Exposure to destructive interparental conflict increases child's risk for psychological problems such as externalizing and internalizing symptoms, impairments in social relationships, and poor academic achievement (Cummings \& Davies, 2010; Grych \& Fincham, 1990; Rhoades, 2008). Due to its role as predictor of a wide array of future adjustment problems (Masten \& Coatsworth, 1998), the latter has become the focus of increasing interest. Previous findings suggest attention performance as one of the major underlying mechanism that may account for the detrimental impact of interparental conflict on child school maladjustment (Davies, Woitach, Winter, \& Cummings, 2008). However, no study has been undertaken, to our knowledge, identifying why certain children may be at higher risk for disruption in attention performance in this context. We addressed this paucity of research by examining the effects of marital discord on children's attentional performance, testing physiological reactivity and child's history of interparental conflict exposure as moderators, in an experimental approach.

Previous work on the emotional security theory (EST; Davies \& Cummings, 1994) provides conceivable explanatory mechanisms in the link between marital strife and child's academic problems. EST posits that maintaining a sense of security and safety in the family setting is a priority goal for children and insecurity is elevated when facing interparental conflict. It holds the sensitization hypothesis stating that children do not get used to conflict between their parents but with repeated exposure the more conflict-sensitive they get and the more intense become their emotional and behavioral responses (Cummings, Zahn-Waxler, \& Radke-Yarrow, 1981; Davies, Sturge-Apple, Winter, Cummings, \& Farrell, 2006). Accordingly, the theory postulates that children from high-conflict homes compared to children experiencing lower levels of marital conflict are more likely to develop negative internal representations of the consequences of parental conflict for the welfare of themselves 
INTERPARENTAL CONFLICT, SCLR, AND CHILD'S ATTENTION

and the family, one of three domains emotional security can be manifested in (Davies \& Cummings, 1994). Although such insecure representations may be adaptive by enhancing children's ability to identify danger cues in high-conflict homes, maladaptive implications for their long-term adjustment are reported. Presuming to serve as schemata for guiding decisions and information processing, they have emerged to be a primary intervening mechanism in the association between interparental conflict and children's academic maladjustment over two years (Sturge-Apple, Davies, Winter, Cummings, \& Schermerhorn, 2008). Beyond, several studies have explored the underlying processes in the relation between children's emotional insecurity and their functioning in the school setting, including (1) the role of sleep disruptions (El-Sheikh, Buckhalt, Cummings, \& Keller, 2007; El-Sheikh, Buckhalt, Keller, Cummings, \& Acebo, 2007), (2) negative peer information processing (e.g., Bascoe, Davies, Sturge-Apple, \& Cummings, 2009), and (3) attention performance (e.g., Davies et al., 2008).

Addressing the latter, Davies and colleagues (2008) found that attention difficulties measured by task assessment and parents' reports accounted for $34 \%$ of the link between insecure representations of the interparental relationship and teacher report on children's school problems. Insecure representations predicted subsequent child attention problems one year later, which in turn were associated with children's academic adjustment both concurrently and longitudinally over a 1-year period (Davies et al., 2008). Therefore, parental discord appears to have substantial impact on child's functioning outside the home too, in particular in school, with attention difficulties as a potential result. Concerns about emotional security following destructive interparental conflict require psychosocial resources which may impair children's neuropsychological functioning, e.g., attention performance (Davies, Winter, \& Cicchetti, 2006). In a similar vein, Davies, Manning, and Cicchetti (2013) recently reported that regulation of emotional insecurity in toddlers seems to cause impairments in other domains of functioning by prioritizing resources toward potential threat. This hypothesis is consistent with resource allocation models postulating that human cognitive processing of 
INTERPARENTAL CONFLICT, SCLR, AND CHILD'S ATTENTION

multiple stimuli is limited by central resources (Kahneman, 1973). To the extent that an individual is burdened with too many distracting stimuli that tap these resources, performance on other tasks will suffer (Schneider \& Fisk, 1982). Given that affective states redirect attentional focus from the task to the affective experience particularly strong (Beal, Weiss, Barros, \& MacDermid, 2005), exposure to parents' arguments may undermine children's short-term attention by disrupting their ability to focus and sustain attention. The purpose of the current study is to examine this assumption taking into consideration children's physiological reactivity to simulated conflict and their parental conflict history as moderators in an experimental approach, using an analogue design.

Analogue studies involving child exposure to simulations of marital conflict are a promising approach particularly in investigating directionality and causality in specific links of interparental conflict dimensions and child's reactivity (Cummings, 1995). Numerous studies have demonstrated the ecological validity of analogue conflict stimuli used as a proxy for real conflicts in this field, providing substantial evidence about the moderating role of children's history of parental discord in the impact of simulated marital conflict on children's reactions in the laboratory setting (e.g., Davies, Sturge-Apple, et al., 2006; El-Sheikh, 1994; O’Brien, Margolin, John, \& Krueger, 1991).

To our knowledge, two experimental studies have examined the immediate effect of interparental conflict on children's cognitive functioning using simulated conflict stimuli to date. First, O'Brien and Chin (1998) reported that 10- to 12-year-old children's responses to audiotaped vignettes of couple conflict interactions biased their recognition memory for conflict-related words assessed by a word recognition task. Children were instructed to listen to constructive and aggressive conflict words and to state whether they had or had not heard them previously in the study (in presented questionnaires or audiotapes). Concerning the aggressive words, children from high-conflict homes compared to children who experienced less frequent parental discord made more false positive memory errors (i.e., aggressive words 
INTERPARENTAL CONFLICT, SCLR, AND CHILD'S ATTENTION

having not been presented in the previous study procedure mistakenly remembered as having been) and fewer false negative memory errors (i.e., number of presented aggressive words that were incorrectly labeled as unknown). In accordance with the sensitization hypothesis, the authors discussed their results as support for the notion that children experiencing frequent marital conflict at home develop insecure representations for interparental conflict that, after experimentally being activated by simulated conflicts, guide information processing and thus affect child's cognitive functions (O’Brien \& Chin, 1998).

Secondly, Medina, Margolin, and Wilcox (2000) determined the impact of children's conflict experiences in the family context on their performance on a verbal attention task, assessed prior to and after exposure to audiotaped vignettes depicting marital conflict. Strikingly, children from families reporting high levels of family hostility improved their scores on auditory attention from pre- to post-stimulus assessment in contrast to children from low-conflict families. Hence, both studies (Medina et al., 2000; O’Brien \& Chin, 1998) have consistently revealed that children's experience of parental conflict significantly moderated the effects of analogue conflict stimuli on their immediate cognitive functioning. Previous findings, however, were limited as no control group with non-conflict stimulus exposure was considered. This research gap will be addressed in the present study.

Medina and colleagues (2000) assumed children's physiological reactivity to be a further crucial variable in this respect which should be assessed in future research. According to the literature physiological arousal assessed by skin conductance level reactivity (SCLR) is considered to be a promising measure. It has been identified as a robust moderator of links between family adversity and maladjustment in children (e.g., Cummings, El-Sheikh, Kouros, \& Keller, 2007). Skin conductance level (SCL) is an electrodermal measure caused by the activity of sweat glands which are innervated solely by the sympathetic branch (SNS) of the autonomic nervous system (ANS). Since SNS activity is predominant in stressful situations, SCLR (i.e., changes in SCL baseline to a stressor) is a particularly useful indicator for the 
INTERPARENTAL CONFLICT, SCLR, AND CHILD'S ATTENTION

ANS activity elicited by stress (Boucsein, 2012). Remarkably, recent research strongly supports the necessity to conceptualize SCLR as a stable individual variable of children across different stressors rather than only a stimulus-evoked physiological response (El-Sheikh, 2007). SCLR to simulated marital discord is emerging as an important moderating mechanism in the association between exposure to interparental conflict and child functioning. El-Sheikh and colleagues found both in a cross-sectional (El-Sheikh, 2005) as well as in a longitudinal study (El-Sheikh, Keller, \& Erath, 2007) that higher SCLR operated as vulnerability-reactive factor in girls; that is, the negative impact of high levels of parental discord on the development of cognitive and externalizing symptoms was exacerbated by high levels of SCLR. These findings suggest that children (predominantly girls) who are particularly physiologically reactive to marital arguments are the most adversely affected.

Therefore, SCLR may help to unravel the impact of marital conflict on child's cognitive functions. The Yerkes-Dodson law postulates an inverted U-shaped curve for the relationship between arousal and cognitive performance. Accordingly, when state of arousal is high, performance decreases (Yerkes \& Dodson, 1908). Easterbrook's (1959) cue utilization hypothesis is frequently used to account for this relationship. Referring to his theory, there is a progressive restriction in the total number of environmental cues that an individual is able to attend to as a function of an increase in arousal. Corresponding to the notion of resource allocation, high levels of arousal reduce the integration of relevant cues and, as a result, performance diminishes (Easterbrook, 1959). Hence, high physiologically reacting children in the face of marital conflict are expected to be particularly impaired in their attention performance.

\section{The current study}

In this study, we examine the role of two moderators that already have been successfully considered in previous studies: (1) SCLR and (2) frequency of interparental conflict at home. The current study examined the impact of a 1-min video exposure on 
INTERPARENTAL CONFLICT, SCLR, AND CHILD'S ATTENTION

children's attention performance, assessed prior to and after stimulus exposure, in two experimental groups. The effects of a videotaped couple conflict were compared to a neutral stimulus and children's baseline attention performance was controlled for. The couple conflict interaction represented a verbal escalating dispute with no conflict resolution, assumed to be particularly prone to elicit child's reaction (e.g., Cummings, Simpson, \& Wilson, 1993). The control group was exposed to an emotionally neutral (i.e., conflict-unrelated) stimulus such as a calm scene of flying birds. This control condition was explicitly chosen because: (1) Using a non-conflict interadult interaction does not match the study objectives. Based on the model of classical conditioning it is likely that even non-conflict adult interaction can trigger negative reactions in children autonomously if previous experiences with aversive interparental interactions were made and parental interaction became a conditioned stimulus evoking conditioned reaction. Fear conditioning has been experimentally proven in healthy children of the age group examined in the current study (Glenn et al., 2012) and seems to be manifested in SCLR particularly (Neumann, Waters, Westbury, \& Henry, 2008). Hence, only a genuine neutral stimulus completely unrelated to adult interaction can avoid such confound. (2) That is, a neutral film condition provides a valuable control stimulus (e.g., see Fowles, Kochanska, \& Murray, 2000), also addressing a gap in the research design of many leading studies in the field.

Children aged 11 to 13 were recruited as evidence exists that at this developmental stage their mental representations of the interparental relationship have become fairly elaborate and play an increasingly important role in information processing (Cummings et al., 1993; Demorest, 1992). Consequently, 10- to 12-year-olds have been found to show schemaconsistent processing of conflict words after exposure to simulations of couple conflict which was not evident in younger children (O’Brien \& Chin, 1998).

Given previous findings about the sensitization hypothesis and the moderating role of SCLR in this regard we expected that children experiencing high levels of interparental 
INTERPARENTAL CONFLICT, SCLR, AND CHILD'S ATTENTION

conflict will differ in their attention performance depending on the experimental condition (couple conflict versus controls) and their physiological reactivity in the following specified direction (hypothesis 1): High-conflict children exposed to the couple conflict compared to the control group are hypothesized to be particularly predisposed for poorer performance in the attention task under conditions of high SCLR (hypothesis 2). In contrast, children from high-conflict homes but characterized by lower levels of SCLR to the conflict stimulus are expected to be less affected in their attention performance than controls (hypothesis 3 ). Due to the small sample size no hypothesis on gender differences was tested.

\section{Method}

\section{Participants}

Participants for this study were 60 children and their mothers. Three outliers (> 3 SD above the mean) with regard to attention performance (i.e., errors of omission) were removed from the analyses because these data points were not compatible with the remaining data. According to the authors of the attention task used in this study (Brickenkamp, SchmidtAtzert, \& Liepmann, 2010) cases for which there is a large gap in the value of performance from the remainder cannot be meaningfully interpreted due to potential simulation or comprehension problems. $N=57$ children (27 boys and 30 girls) and their mothers formed the final sample. Mean age of the children was 11.64 years $(S D=.74$, range $=11-13$ years $)$. All children were living together with both their biological parents except for 3 children who were living with their biological mother and their stepfather since toddler age. Seventy-two percent attended elementary school, 19\% secondary school, and 9\% another type of school. The mothers' age averaged 42.93 years $(S D=3.87$, range $=31-52$ years). Most $(96 \%)$ were married, $4 \%$ were cohabiting. Relationship duration ranged from 7 to 28 years $(M=18.40$ years, $S D=4.39)$. Mothers were primarily Swiss $(82 \%), 8 \%$ were Germans and $10 \%$ were from other countries, but all were fluent in German. Four percent completed secondary school, 37\% graduated vocational school, and 59\% attained higher educational qualification, 
INTERPARENTAL CONFLICT, SCLR, AND CHILD'S ATTENTION

respectively.

Participants were recruited by means of advertisements in newspapers or magazines and information letters for parents sent home with children from local public schools. Inclusion criteria for participation were the child being between 11 and 13 years of age, that both mother and child were fluent in German, and that they were living together with the child's father or stepfather in the same household.

\section{Procedure}

Assessment of eligible mothers and children took place in our lab. After the introduction by the examiner, mothers were asked to sign the consent form. Subsequently, the child was told that the mother would be next door for the remainder of the assessment session. Mothers and children completed a set of questionnaires separately (mothers completed them online). After a short adaptation period once electrodes having been attached, children's SCL was then first measured for a 3-min baseline period. Pictures neutral in valence of the International Affective Picture System (IAPS; Lang, Bradley, \& Cuthbert, 2008) which have been validated concerning self-report and SCL (Lang, Greenwald, Bradley, \& Hamm, 1993) were shown during this period. Next, SCL was recorded while children were viewing a 1-min video sequence. They were randomly assigned to two experimental video conditions $(n=28$ to the couple conflict and $n=29$ to the neutral scene, respectively). Block randomization was used to implement the random assignment to condition in order to ensure an equal allocation to conditions. The person responsible for the random assignment to condition was not involved in the assessment of outcomes.

Group 1 (i.e., the couple conflict group) was exposed to a 1-min videotaped couple argument depicting verbal anger of the woman, complaining about her husband's lack of understanding of her daily exhaustion and the husband's reaction which included a high level of defensiveness. The argument ended unresolved in shouting by the wife and displaying contempt by the husband. Due to ethical concerns no intense interpersonal hostility or 
INTERPARENTAL CONFLICT, SCLR, AND CHILD'S ATTENTION

aggressiveness (i.e., interparental violence) was presented. Group 2 (i.e., the control group) was shown a neutral scene of equal length showing flying birds, representing a peaceful and calm stimulus. The sequence of a nature film was chosen as a conflict-unrelated control condition excluding any interpersonal aspects.

Prior to and after video exposure, all children completed the d2-R test of attention (Brickenkamp et al., 2010). This paper-pencil cancellation test consists of 14 rows each of 57 characters ("p" and "d" with one to four dashes above and/or below each letter), whereby the first and the last row are not included in the calculation of the processing measures. All " $\mathrm{d}$ " with two dashes, regardless where they appear, are target symbols. The subjects were asked to cancel as many target symbols as possible within 20 seconds per row. Total test time is 4' $40^{\prime \prime}$ without pause between test rows.

At the end, all children were thoroughly debriefed by the examiner. They were told that conflicts were a common occurrence in normal family life but that constructive conflict resolutions were important. The debriefing happened first alone, then with the mother present. Participation in the present study was not rewarded financially. However, each mother was given a CCET-DVD (Bodenmann, Schaer, \& Gmelch, 2008), a self-directed marital distress prevention tool based on the Couples Coping Enhancement Training (CCET; Bodenmann \& Shantinath, 2004) and they were able to obtain a report of the study after its completion. The children received a bag of sweets and a certificate for participating in the family study.

\section{Measures}

Attention performance. Children's attention performance was measured using the d2-R test of attention (Brickenkamp et al., 2010). This test provides a number of scores, one of them is relevant to this investigation. Errors of omission are the sum of number of target symbols not cancelled by the subject. While there is controversy regarding the meaning of commission errors in attention tasks there is much more consensus that errors of omission reliably indicates inattention (Trommer, Hoeppner, Lorber, \& Armstrong, 1988). The d2 test 
INTERPARENTAL CONFLICT, SCLR, AND CHILD'S ATTENTION

is a frequently used neuropsychological tool in German speaking countries. Reliability and validity of the revised version have been examined comprehensively with Cronbach's alpha within the relevant age range of $.81-.86$ concerning errors of omission (Brickenkamp et al., 2010).

Frequency of interparental conflict. One subscale of the German short version of the Children's Perception of Interparental Conflict Scale (Gödde \& Walper, 2001) developed originally by Grych, Seid, and Fincham (1992) was used to assess children's perceptions of frequency of interparental conflict. A largely consistent factor structure to the American original and good psychometric properties have been shown (Gödde \& Walper, 2001). The children completed the three items (e.g., My parents are mean to each other) of the subscale Frequency on a 5-point Likert scale ranging from 1 (never) to 5 (very often). Internal consistency was $\alpha=.72$ in the current study.

Skin conductance level reactivity (SCLR). SCL was measured for a 3-min baseline period and continuously throughout video exposure using two $\mathrm{Ag}-\mathrm{AgCl}$ electrodes filled with isotonic electrode gel ( $0.5 \%$ saline in a neutral base). The electrodes were placed on the volar surfaces of the distal phalanges of the first and second fingers of the child's non-dominant hand having been washed with pure water. An SCL response amplifier using a constant voltage $(0.5 \mathrm{~V})$ technique to measure skin conductance and a16 channel A/D converter were used to amplify and digitize the signals. The AcqKnowledge data acquisition and analysis software by Biopac Systems, Inc. collected SCL assessments at a rate of 1000 readings per second. Averages (expressed in microSiemens) for SCL during the baseline and the stimulus exposure period were calculated. SCLR in response to the video exposure was obtained by subtracting SCL baseline from SCL during viewing the respective video. SCL data was not available for 4 children because of equipment failure or measurement artifacts. These children were excluded from the whole study.

\section{Data analysis}


INTERPARENTAL CONFLICT, SCLR, AND CHILD'S ATTENTION

Hierarchical multiple regression analyses were used to examine SCLR and frequency of interparental conflict as moderators in the link between video condition and performed errors of omission at post-stimulus assessment (Cohen, Cohen, West, \& Aiken, 2002). Performance of omission errors prior to the stimulus was controlled for, entering it in the first step of the regression analysis. The child's experimental condition (i.e., a dummy-coded variable indicating the couple conflict group with the control condition as reference group), perceived frequency of interparental conflict, and SCLR followed in the second step. In the third step, all two-way interactions between frequency of interparental conflict, SCLR, and the experimental condition were entered. The three-way product of frequency of interparental conflict, SCLR, and child's experimental condition formed the last step. All numerical predictors were grand mean centered in order to simplify the interpretation of significant interactions and to eliminate nonessential multicollinearity (Aiken \& West, 1991).

\section{Results}

\section{Preliminary analyses}

Preliminary analyses in the form of t-tests evidenced that random assignment was successful as there were no significant differences between the two experimental groups for any of the study variables (see Table 1). Additionally, a chi-square test was computed in order to assure that boys and girls were equally distributed across the two experimental conditions $(\chi(1)=2.11, n s$.$) . As presented in Table 1$, the study variables were not significantly intercorrelated with the expected exception of the association between children's pre- and post-stimulus performed errors of omission. 
INTERPARENTAL CONFLICT, SCLR, AND CHILD'S ATTENTION

Table 1

Means, standard deviations, $t$-tests between experimental groups, and correlations among study variables

\begin{tabular}{|c|c|c|c|c|c|c|}
\hline & 1 & 2 & 3 & $\begin{array}{c}\text { Group } 1 \\
M(S D) \\
\end{array}$ & $\begin{array}{c}\text { Group } 2 \\
M(S D) \\
\end{array}$ & $t$ \\
\hline 1. $\mathrm{IPC}^{\mathrm{a}}$ & - & & & $2.26(.84)$ & $2.08(.81)$ & $t(55)=-.83$ \\
\hline 2. $\mathrm{SCLR}^{\mathrm{b}}$ & .08 & - & & $1.38(1.14)$ & $2.17(2.07)$ & $t(55)=1.77$ \\
\hline 3. Omission errors (pre-stimulus) & -.06 & .21 & - & $8.71(8.50)$ & $7.59(4.42)$ & $t(55)=-.63$ \\
\hline 4. Omission errors (post-stimulus) & -.08 & .12 & $.60 * *$ & $4.93(3.96)$ & $4.76(3.93)$ & $t(55)=-.16$ \\
\hline
\end{tabular}

Note. ${ }^{\mathrm{a}} \mathrm{IPC}=$ frequency of interparental conflict; ${ }^{\mathrm{b}} \mathrm{SCLR}=$ skin conductance level reactivity; group $1=$ couple conflict group; group $2=$ control group. ${ }^{*} p=.000$. 
INTERPARENTAL CONFLICT, SCLR, AND CHILD'S ATTENTION

\section{Main results}

As shown in Table 2, the hierarchical multiple regression analysis revealed that the children's attention performance prior to the stimulus exposure significantly predicted poststimulus performed errors of omission, as expected. The two-way product term of SCLR and child's perception of interparental conflict emerged as significant without consideration of the experimental groups $(b=-1.00, p=.018$; see Table 2$)$. However, results must be discussed in relation to a significant three-way interaction once the experimental condition was taken into account $(\mathrm{b}=1.36, p=.047$; see Table 2).

Following Aiken and West (1991), the three-way interaction was interpreted by plotting the simple regression lines for high and low values of the moderators, and the simple slopes were further examined whether they were significantly different from zero. According to the recommendation of Cohen and Cohen (1983), lower and higher levels of moderators were defined as 1 standard deviation above (+1 SD) and below (-1 SD) the mean, respectively. With the pivotal requirement that the conditional values of the moderator designated for plotting and testing interactions should be meaningful (Preacher, Curran, \& Bauer, 2006), we first confirmed that $+/-1.0$ standard deviation of SCLR and frequency of interparental conflict fell inside the range of the observed data in the subsamples of both study groups separately. Likewise, SCLR values of the high-conflict subgroups $(+1 S D$ in interparental conflict) included the range of $+/-1.0$ standard deviation. 
INTERPARENTAL CONFLICT, SCLR, AND CHILD’S ATTENTION

Table 2

SCLR and frequency of interparental conflict as moderatorsof the impact of experimental condition on post-stimulus performed errors of omission

\begin{tabular}{lccccc}
\hline Predictors & $\mathrm{b}$ & $p$ & $\Delta R^{2}$ & $p$ & $R^{2}$ \\
\hline Step1 & & & .36 & .000 & .36 \\
$\quad$ Omission errors (pre-stimulus) & .32 & .000 & & & \\
Step 2 & & & .00 & $\mathrm{~ns}$ & .37 \\
$\quad$ Experimental condition & -.38 & $\mathrm{~ns}$ & & & \\
$\quad$ IPC & .71 & $\mathrm{~ns}$ & & & \\
$\quad$ SCLR & -.16 & $\mathrm{~ns}$ & & & \\
Step 3 & & & 0.05 & $\mathrm{~ns}$ & .41 \\
$\quad$ Experimental condition * IPC & -1.18 & $\mathrm{~ns}$ & & & \\
$\quad$ Experimental condition * SCLR & .40 & $\mathrm{~ns}$ & & & \\
$\quad$ IPC * SCLR & -1.00 & .018 & & & \\
Step 4 & & & 0.03 & .047 & .45 \\
$\quad$ Experimental condition * IPC * SCLR & 1.36 & .047 & & & \\
\hline
\end{tabular}

Note. Unstandardized regression coefficients of the last step are reported. ${ }^{a} \mathrm{IPC}=$ frequency of interparental conflict; ${ }^{\mathrm{b}} \mathrm{SCLR}=$ skin conductance level reactivity; outcome variable = post-stimulus performed errors of omission. 
INTERPARENTAL CONFLICT, SCLR, AND CHILD'S ATTENTION

Depicted in Figure 1 is the link between the experimental video condition and children's attention performance plotted separately for children from high- and low-conflict homes at higher and lower levels of SCLR. As expected, it is shown that the impact of children's history of frequent interparental conflict was different in the two study groups depending on their physiological reactivity. To test hypothesis 1 beyond the regression analysis, a slope difference test (Dawson \& Richter, 2006) was computed which indicated a significant difference between the two regression lines for children from high-conflict homes in the expected direction $(t(48)=1.69, p=.049)$. That is, at high levels of interparental conflict, children's attention performance varied as a function of experimental condition (exposure to couple conflict versus controls) and physiological arousability. More specifically and in accordance with hypothesis 3, the simple slope test revealed that children from highconflict homes exposed to the couple conflict made fewer omission errors than the controls when not highly aroused (i.e., low SCLR) by the video stimulus $(\mathrm{b}=-3.93, t(48)=-1.96, p=$ .028). This association manifested in the reverse direction under conditions of high physiological reactivity, that is, children from high-conflict homes exposed to the couple conflict compared to controls evidenced worse performance when highly aroused (i.e., high SCLR). However, the simple slope was not statistically significant and therefore hypothesis 2 was not supported by this test. 
INTERPARENTAL CONFLICT, SCLR, AND CHILD’S ATTENTION

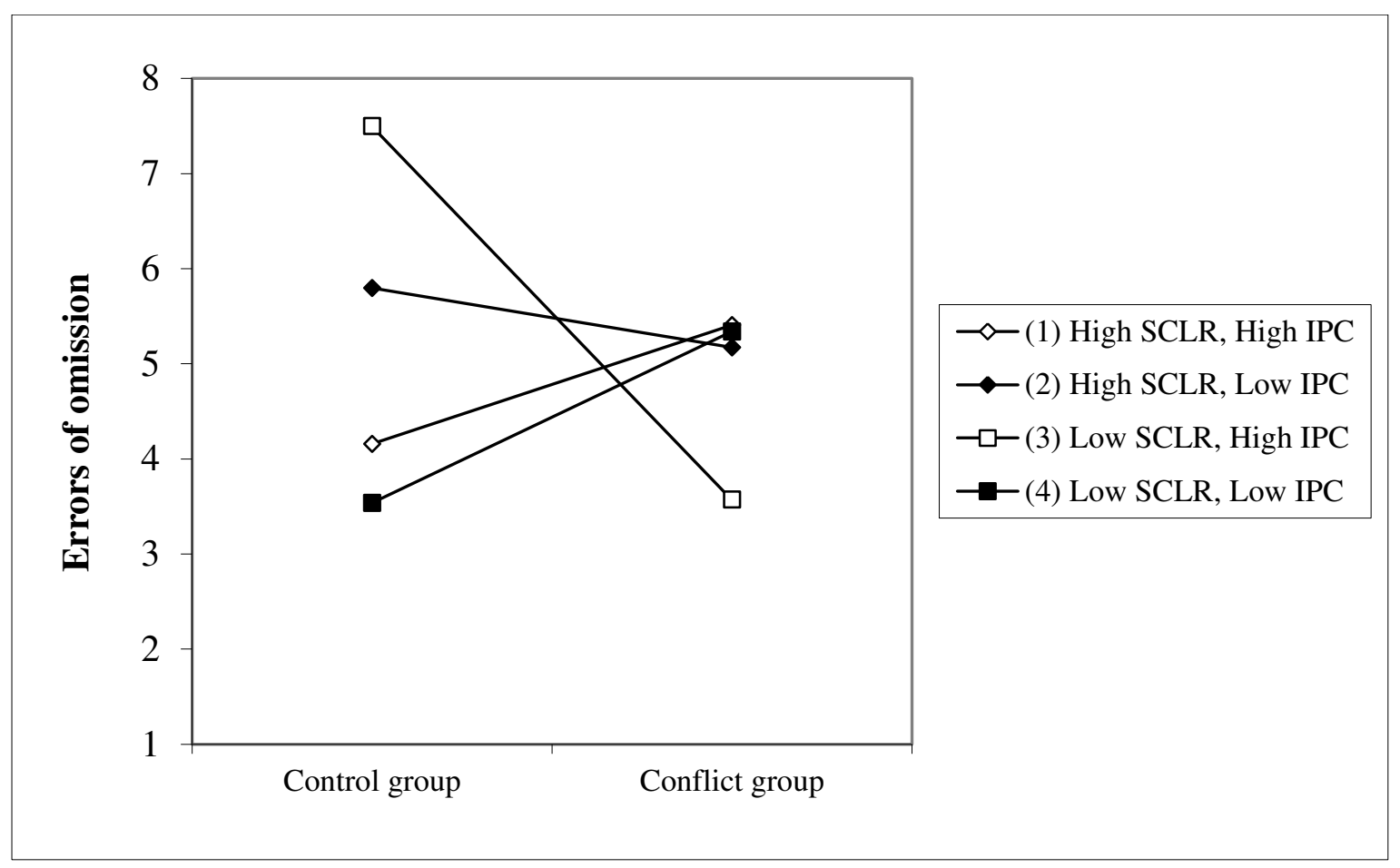

Figure 1. The effect of experimental condition on post-stimulus performed errors of omission moderated by skin conductance level reactivity (SCLR) and frequency of interparental conflict (IPC) controlled for pre-stimulus performed errors of omission. 
INTERPARENTAL CONFLICT, SCLR, AND CHILD'S ATTENTION

Considering children reporting low levels of parental arguments, post-stimulus performed errors of omission were not different between experimental groups as a function of physiological arousal. The slope difference test did not reveal a significant difference between the two regression lines for children from low-conflict homes and the simple slopes were not significant at either high or low values of physiological reactivity. Since literature in this context is much sparser no hypotheses had been formulated.

\section{Discussion}

This is the first study, to the best of our knowledge, to test the effects of marital conflict on children's short-termed attention performance under consideration of their history of interparental conflict and physiological reactivity to a simulated couple conflict compared to controls. Children's attention was assessed prior to and immediately after a 1-min video exposure and SCLR was measured continuously throughout stimulus presentation. Whilst definite conclusions are precluded by the small sample size, the present study is unique in providing new insights about the negative impact of marital conflict on child's attentional performance. Both children's experiences with parental discord and SCLR were confirmed as moderators in this link. Replicating an abundance of literature, our results indicate that not all children are similarly affected by exposure to interparental disputes (in this instance, experimental versus control condition) but, in agreement with the emotional security theory, the effects are also determined by (1) the child's former family background of marital conflict as well as (2) child characteristics, such as stress reactivity (Cummings \& Davies, 2002).

First, considerable evidence has supported the sensitization hypothesis that frequent exposure to parental conflict engenders children's progressively higher reactions to future parental arguments or experimental simulations of conflicts (e.g., Cummings et al., 1981; Davies, Myers, Cummings, \& Heindel, 1999). This study is consistent with previous findings that children's history of interparental conflict might be one of the decisive factors in the short-term impact of marital conflict on their 
INTERPARENTAL CONFLICT, SCLR, AND CHILD'S ATTENTION

cognitive functions in terms of memory biases (O’Brien \& Chin, 1998) and verbal attention (Medina et al., 2000). Secondly, child's dispositional physiological reactivity is identified to be an important moderating mechanism in the link between interparental conflict and child outcomes (Cummings \& Davies, 2002). The research by El-Sheikh and colleagues correspond to this notion reporting SCLR to conflict simulations exacerbates the risk of high levels of marital conflict in girls (El-Sheikh, Keller, \& Erath, 2007; El-Sheikh, 2005).

The current study tried to contribute to a better understanding of child attention difficulties by comparing the effects of a parental argument with a control stimulus. Taken together, our pattern of results suggests that children's perceptions of the frequency of interparental conflict in the home and their physiological reactivity measured by SCLR moderated the influence of the experimental stimulus on child's short-term attention performance, but differently depending on whether children were exposed to a marital conflict or to a conflict-unrelated stimulus. This finding affirms the validity of the study and the viability of the present hypotheses; that is, that the effects of two prominent moderators explored in this field are unique for explaining immediate reactivity to marital conflict in terms of children's cognitive functioning. Conclusions to children from low-conflict families are not possible as the moderation effect was primarily driven by children reporting frequent interparental discord. Under conditions of low SCLR values children from high-conflict homes made significantly fewer errors in the attention task after video exposure compared to the controls. Thus, as expected, lower physiological reactivity to the stimulus acted as a protective factor in children from highconflict homes exposed to the couple conflict. Our findings do not completely match previous reports (El-Sheikh, Keller, \& Erath, 2007; El-Sheikh, 2005). More specifically, they found that higher levels of SCLR emerged as vulnerability factor in the link of marital conflict and girls' cognitive and externalizing problems. The reported results do not definitely support the vulnerability hypothesis of high SCLR since we failed to find a significant simple slope in children from high-conflict families at high values of SCLR and therefore differences between the two experimental groups could not be 
INTERPARENTAL CONFLICT, SCLR, AND CHILD'S ATTENTION

interpreted. However, caution is warranted in comparing the results since former studies (El-Sheikh, Keller, \& Erath, 2007; El-Sheikh, 2005) examined parents' reports of child maladjustment as a trait measure by means of questionnaires. There is increasing evidence that intense and prolonged SNS activation causes wear and tear on the body systems which is linked with multiple adjustment problems in the long term, whereas far less is known about its short-term impact.

The immediate impact of conflict simulations to children's attention performance has been tested in a previous study but without regard to physiological reactivity and no comparison to a conflict-unrelated stimulus has been considered (Medina et al., 2000). The results reported here shed light on their, at first view, counterintuitive finding that children experiencing higher family hostility enhanced their performance after conflict exposure compared to children from low-hostility homes. As the authors argued, induced physiological arousal may in fact be important to consider; that is, our study indicates that only children from high-conflict family backgrounds who do not get highly physiologically aroused regarding skin conductance seem to be able to invest their attentional resources particularly efficiently. From the standpoint of resource allocation theories this conclusion appears plausible considering the assumption that under low arousal levels individuals are better capable of focusing the bulk of attentional resources on a given task instead on conditions surrounding their arousing state resulting in a restricted central resource pool (Beal et al., 2005). Apparently, the process of resource allocation fails to explain why electrodermal underarousal was beneficial for children's attention performance in the couple conflict group, but not in the control group. Interpretation in the light of the behavioral inhibition system (BIS) of the two-factor learning theory by Gray (1975) might be helpful for this purpose. The BIS is an arousal system responding to threatening or aversive stimuli by producing anxiety which inhibits rather than energizes behavior (also referred to as anxiety system; Gray, 1976). There is increasing evidence that electrodermal activity is a strong indicator for BIS activation (Fowles, 1980). Fowles and colleagues (2000) reported that young children's skin conductance lability, a measure of the cumulative effects of 
INTERPARENTAL CONFLICT, SCLR, AND CHILD'S ATTENTION

SCLR to various experimental stimuli, was significantly correlated with child's observed fearfulness and inhibitory control as two components of the BIS. Low behavioral inhibition, reflected in low SCLR, constitutes a condition of poor fear conditioning manifested in low anxiety when faced with aversive stimuli (Fowles et al., 2000). This pattern might be conducive for children reporting high levels of marital conflict having been exposed to the couple argument since it may have the potential to mitigate their increased sensitivity. Conversely, heightened BIS activity, which is characterized by passive and fearful behavioral tendencies (Beauchaine, 2001), has to be considered as highly dysfunctional in this context. Electrodermal underarousal in response to an emotionally neutral stimulus, respectively, may affect child's attention adversely by the disability to focus resources of information processing. A conclusion that, in the clinical context, has led to the underactive BIS hypothesis for attention deficit hyperactivity disorder in children (Quay, 1997).

Several limitations of this study and corresponding directions for future research merit discussion. First, substantial precaution is required when interpreting the present findings because of the low power immanent in small sample sizes. In particular, the three-way interactions must be interpreted with caution and further studies are needed to support the reliability and stability of these findings. Beyond, the examined non-significant simple slopes might reveal significant in larger samples. Second, it is important to comment that the effect sizes of the interactions were modest in magnitude. Experimental studies, however, are known to be highly efficient to detect moderator effects but most often yield small effect sizes (McClelland \& Judd, 1993). Third, in order to maximize the possibility to detect effects by reducing statistical distortions in the present sample, only interaction terms of primary theoretical interest were included in the regression analyses (Cohen $\&$ Cohen, 1983). Given that available data reported gender differences in the moderating role of SCLR the lack of consideration of child gender in the interactions has to be regarded as limitation and additional studies are needed to clarify whether the presented results differ in boys and girls. Likewise, El-Sheikh and colleagues (2009) advocated the emerging hypothesis that the joint 
INTERPARENTAL CONFLICT, SCLR, AND CHILD'S ATTENTION

influence of sympathetic and vagal activity might be particularly predictive of children's attention difficulties in the context of interparental conflict. Examinations of physiological systems as independent entities must be regarded as inherently limited which should be considered in future research. Fourth, the present study used a conflict-unrelated stimulus without any adult interaction as control condition in order to avoid arousal in children due to potential previous classical conditioning of interparental conversations. Our finding that SCLR was not significantly different between the two experimental groups is consistent with Fowles et al. (2000) reporting that (positive and negative) emotional films did not evoke higher SCL in children compared to neutral films. It seems that already video exposure goes along with physiological arousal in children largely independently of content; hence we believe that variables distinctive from the couple conflict scenario (e.g., species, setting, and vocalizations) may have a less important influence than just watching a videotape. However, we cannot completely rule out that these variables may have an impact above and beyond this unspecific arousal. To compare a marital conflict with either a constructive dispute or a neutral interparental conversation is therefore an important future research direction. Fifth, since experimentally in nature, this study focused on short-termed effects of parental conflict on child's attention performance. Although Davies et al. (2008) documented attention difficulties to be one of the key pathogenic processes in the impact of emotional security on child's school adjustment we cannot establish from our data, albeit plausible, whether the presented mechanisms might undermine academic performance in the longer term. In a similar vein, though considerations from the EST were discussed as one of the pivotal theoretical frameworks of the present study, we did not measure emotional security and it is thus not possible to draw conclusions in this regard. Therefore, additional studies employing more sophisticated research designs, including longitudinal data, are needed.

Notwithstanding these limitations, the present study has potential strengths. These include the experimental design involving controls allowing investigation of causal relationships, the performance task for assessing children's attention, and measurement of SCLR in response to marital 
INTERPARENTAL CONFLICT, SCLR, AND CHILD'S ATTENTION

conflict exposure. The current findings advance theory and research literature on the impact of marital conflict on child's functioning indicating that physiological stress reactivity and children's experiences with interparental conflict are crucial when discussing why some children might be at higher risk for the development of attention problems in this connection. Our results are particularly notable given (1) the short duration of the conflict stimulus (1 minute) considering that real parental conflicts usually last longer, (2) the impact of the children's own parents is presumably much stronger, and (3) no intense interparental hostility or violence, but an angry child-unrelated interaction, formed the stimulus. In sum, it has to be assumed that effects in real life might be much more salient. If results are replicated elsewhere it may yield important practical implications about prevention of children's attention difficulties in relation to marital conflict exposure. 
INTERPARENTAL CONFLICT, SCLR, AND CHILD'S ATTENTION

\section{References}

Aiken, L. S., \& West, S. G. (1991). Multiple regression: Testing and interpreting interactions. Newbury Park, CA: Sage.

Bascoe, S. M., Davies, P. T., Sturge-Apple, M. L., \& Cummings, E. M. (2009). Children's representations of family relationships, peer information processing, and school adjustment. Developmental Psychology, 45(6), 1740-1751. doi:10.1037/a0016688

Beal, D. J., Weiss, H. M., Barros, E., \& MacDermid, S. M. (2005). An episodic process model of affective influences on performance. Journal of Applied Psychology, 90(6), 1054-1068. doi:10.1037/0021-9010.90.6.1054

Beauchaine, T. (2001). Vagal tone, development, and Gray's motivational theory: Toward an integrated model of autonomic nervous system functioning in psychopathology. Development and Psychopathology, 13(02), 183-214.

Bodenmann, G., Schaer, M., \& Gmelch, S. (2008). Paarlife - Glücklich zu zweit trotz Alltagsstress. [DVD]

Bodenmann, G., \& Shantinath, S. D. (2004). The Couples Coping Enhancement Training (CCET): A new approach to prevention of marital distress based upon stress and coping. Family Relations, 53(5), 477-484. doi:10.1111/j.0197-6664.2004.00056.x

Boucsein, W. (2012). Electrodermal activity. New York: Springer.

Brickenkamp, R., Schmidt-Atzert, L., \& Liepmann, D. (2010). Test d2 - Revision. Aufmerksamkeitsund Konzentrationstest: Manual [Test d2 - Revision. Attention and concentration test: Manual]. Göttingen: Hogrefe.

Cohen, J., \& Cohen, P. (1983). Applied multiple regression/correlation analysis for the behavioral sciences. (Vol. 2). Hillsdale, NJ: Erlbaum.

Cohen, J., Cohen, P., West, S. G., \& Aiken, L. S. (2002). Applied multiple regression/correlation analysis for the behavioral sciences (3rd ed.). Mahwah, NJ: Lawrence Erlbaum. 
INTERPARENTAL CONFLICT, SCLR, AND CHILD'S ATTENTION

Cummings, E. M. (1995). Usefulness of experiments for the study of the family. Journal of Family Psychology, 9(2), 175-185. doi:10.1037/0893-3200.9.2.175

Cummings, E. M., \& Davies, P. T. (2002). Effects of marital conflict on children: Recent advances and emerging themes in process-oriented research. Journal of Child Psychology and Psychiatry, 43(1), 31-63. doi:10.1111/1469-7610.00003

Cummings, E. M., \& Davies, P. T. (2010). Marital conflict and children. An emotional security perspective. New York: The Guilford Press.

Cummings, E. M., El-Sheikh, M., Kouros, C. D., \& Keller, P. S. (2007). Children's skin conductance reactivity as a mechanism of risk in the context of parental depressive symptoms. Journal of Child Psychology and Psychiatry, 48(5), 436-445. doi:10.1111/j.1469-7610.2006.01713.x

Cummings, E. M., Simpson, K. S., \& Wilson, A. (1993). Children's responses to interadult anger as a function of information about resolution. Developmental Psychology, 29, 978-985. doi:10.1037/0012-1649.29.6.978

Cummings, E. M., Zahn-Waxler, C., \& Radke-Yarrow, M. (1981). Young children's responses to expressions of anger and affection by others in the family. Child Development, 52, 1274 1282.

Davies, P. T., \& Cummings, E. M. (1994). Marital conflict and child adjustment: An emotional security hypothesis. Psychological Bulletin, 116(3), 387-411. doi:10.1037/00332909.116.3.387

Davies, P. T., Manning, L. G., \& Cicchetti, D. (2013). Tracing the cascade of children's insecurity in the interparental relationship: The role of stage-salient tasks. Child Development, 84(1), 297 312. doi:10.1111/j.1467-8624.2012.01844.x

Davies, P. T., Myers, R. L., Cummings, E. M., \& Heindel, S. (1999). Adult conflict history and children's subsequent responses to conflict: An experimental test. Journal of Family Psychology, 13(4), 610-628. doi:10.1037/0893-3200.13.4.610 
INTERPARENTAL CONFLICT, SCLR, AND CHILD'S ATTENTION

Davies, P. T., Sturge-Apple, M., Winter, M., Cummings, E., \& Farrell, D. (2006). Child adaptational development in contexts of interparental conflict over time. Child Development, 77(1), 218233. doi:10.1111/j.1467-8624.2006.00866.x

Davies, P. T., Winter, M. A., \& Cicchetti, D. (2006). The implications of emotional security theory for understanding and treating childhood psychopathology. Development and Psychopathology, 18(3), 707-735. doi:10.1017/S0954579406060354

Davies, P. T., Woitach, M. J., Winter, M. A., \& Cummings, E. M. (2008). Children's insecure representations of the interparental relationship and their school adjustment: The mediating role of attention difficulties. Child Development, 79(5), 1570-1582. doi:10.1111/j.14678624.2008.01206.x

Dawson, J. F., \& Richter, A. W. (2006). Probing three-way interactions in moderated multiple regression: Development and application of a slope difference test. Journal of Applied Psychology, 91(4), 917-926. doi:10.1037/0021-9010.91.4.917

Demorest, A. P. (1992). The role of social cognition in children's social maladjustment. Social Cognition, 10(2), 211-233. doi:10.1521/soco.1992.10.2.211

Easterbrook, J. A. (1959). The effect of emotion on cue utilization and the organization of behavior. Psychological Review, 66(3), 183-201.

El-Sheikh, M. (1994). Children's emotional and physiological responses to interadult angry behavior: The role of history of interparental hostility. Journal of Abnormal Child Psychology, 22(6), 661-678. doi:10.1007/BF02171994

El-Sheikh, M. (2005). The role of emotional responses and physiological reactivity in the marital conflict-child functioning link. Journal of Child Psychology and Psychiatry, 46(11), 11911199. doi:10.1111/j.1469-7610.2005.01418.x

El-Sheikh, M. (2007). Children's skin conductance level and reactivity: Are these measures stable over time and across tasks? Developmental Psychobiology, 49(2), 180-186. 
INTERPARENTAL CONFLICT, SCLR, AND CHILD'S ATTENTION

doi:10.1002/Dev.20171

El-Sheikh, M., Buckhalt, J. A., Cummings, E. M., \& Keller, P. (2007). Sleep disruptions and emotional insecurity are pathways of risk for children. Journal of Child Psychology and Psychiatry, 48(1), 88-96. doi:10.1111/j.1469-7610.2006.01604.x

El-Sheikh, M., Buckhalt, J. A., Keller, P. S., Cummings, E. M., \& Acebo, C. (2007). Child emotional insecurity and academic achievement: The role of sleep disruptions. Journal of Family Psychology, 21(1), 29-38. doi:Doi 10.1037/0893-3200.21.1.29

El-Sheikh, M., Keller, P. S., \& Erath, S. A. (2007). Marital conflict and risk for child maladjustment over time: Skin conductance level reactivity as a vulnerability factor. Journal of Abnormal Child Psychology, 35(5), 715-727. doi:10.1007/s10802-007-9127-2

El-Sheikh, M., Kouros, C. D., Erath, S., Cummings, E. M., Keller, P., \& Staton, L. (2009). Marital conflict and children's externalizing behavior: Pathways involving interactions between parasympathetic and sympathetic nervous system activity. Monographs of the Society for Research in Child Development, 74(1), vii-79. doi:10.1111/j.1540-5834.2009.00501.x

Fowles, D. C. (1980). The three arousal model: Implications of Gray's two-factor learning theory for heart rate, electrodermal activity, and psychopathy. Psychophysiology, 17(2), 87-104. doi:10.1111/j.1469-8986.1980.tb00117.x

Fowles, D. C., Kochanska, G., \& Murray, K. (2000). Electrodermal activity and temperament in preschool children. Psychophysiology, 37(6), 777-787. doi:10.1111/1469-8986.3760777

Glenn, C. R., Klein, D. N., Lissek, S., Britton, J. C., Pine, D. S., \& Hajcak, G. (2012). The development of fear learning and generalization in 8-13 year-olds. Developmental Psychobiology, 54(7), 675-684. doi:10.1002/dev.20616

Gödde, M., \& Walper, S. (2001). Elterliche Konflikte aus der Sicht von Kindern und Jugendlichen: Die deutsche Kurzfassung der Children's Perception of Interparental Conflict Scale (CPIC). [The German short version of the Children's Perception of Interparental Conflict Scale]. 
INTERPARENTAL CONFLICT, SCLR, AND CHILD'S ATTENTION

Diagnostica, 47(1), 18-26. doi:10.1026//0012-1924.47.1.18

Gray, J. A. (1975). Elements of a two-process theory of learning. New York: Academic Press.

Gray, J. A. (1976). The behavioural inhibition system: A possible substrate for anxiety. In M. P. Feldman \& A. M. Broadhurst (Eds.), Theoretical and experimental bases of behaviour modification. (pp. 3-41). New York: Wiley.

Grych, J. H., \& Fincham, F. D. (1990). Marital conflict and children's adjustment: A cognitivecontextual framework. Psychological Bulletin, 108(2), 267-290.

Grych, J. H., Seid, M., \& Fincham, F. D. (1992). Assessing marital conflict from the child's perspective: The Children's Perception of Interparental Conflict Scale. Child Development, 63(3), 558-572.

Kahneman, D. (1973). Attention and effort. Englewood Cliffs, NJ: Prentice-Hall.

Lang, P. J., Bradley, M. M., \& Cuthbert, B. N. (2008). International affective picture system (IAPS): Affective ratings of pictures and instruction manual. Technical Report A-8. University of Florida, Gainesville, FL.

Lang, P. J., Greenwald, M. K., Bradley, M. M., \& Hamm, A. O. (1993). Looking at pictures: Affective, facial, visceral, and behavioral reactions. Psychophysiology, 30(3), 261-273. doi:10.1111/j.1469-8986.1993.tb03352.x

Masten, A. S., \& Coatsworth, J. D. (1998). The development of competence in favorable and unfavorable environments: Lessons from research on successful children. American Psychologist, 53(2), 205-220. doi:10.1037/0003-006X.

McClelland, G. H., \& Judd, C. M. (1993). Statistical difficulties of detecting interactions and moderator effects. Psychological Bulletin, 114(2), 376-390. doi:10.1037/00332909.114.2.376

Medina, A. M., Margolin, G., \& Wilcox, R. R. (2000). Family hostility and children's cognitive processes. Behavior Therapy, 31(4), 667-684. doi:10.1016/S0005-7894(00)80037-4 
INTERPARENTAL CONFLICT, SCLR, AND CHILD'S ATTENTION

Neumann, D. L., Waters, A. M., Westbury, H. R., \& Henry, J. (2008). The use of an unpleasant sound unconditional stimulus in an aversive conditioning procedure with 8- to 11-year-old children. Biological Psychology, 79(3), 337-342. doi:10.1016/j.biopsycho.2008.08.005

O’Brien, M., \& Chin, C. (1998). The relationship between children's reported exposure to interparental conflict and memory biases in the recogniton of aggressive and constructive conflict words. Personality and Social Psychology Bulletin, 24(6), 647-656. doi:10.1177/0146167298246008

Preacher, K. J., Curran, P. J., \& Bauer, D. J. (2006). Computational tools for probing interactions in multiple linear regression, multilevel modeling, and latent curve analysis. Journal of Educational and Behavioral Statistics, 31(4), 437-448. doi:10.2307/4122453

Quay, H. C. (1997). Inhibition and attention deficit hyperactivity disorder. Journal of Abnormal Child Psychology, 25(1), 7-13. doi:10.1023/A:1025799122529

Rhoades, K. A. (2008). Children's responses to interparental conflict: A meta-analysis of their associations with child adjustment. Child Development, 79(6), 1942-1956. doi:10.1111/j.1467-8624.2008.01235.x

Schneider, W., \& Fisk, A. D. (1982). Concurrent automatic and controlled visual search: Can processing occur without resource cost? Journal of Experimental Psychology: Learning Memory and Cognition, 8(4), 261-278. doi:10.1037/0278-7393.8.4.261

Sturge-Apple, M. L., Davies, P. T., Winter, M. A., Cummings, E. M., \& Schermerhorn, A. (2008). Interparental conflict and children's school adjustment: The explanatory role of children's internal representations of interparental and parent-child relationships. Developmental Psychology, 44(6), 1678-1690. doi:10.1037/a0013857

Trommer, B. L., Hoeppner, J.-A. B., Lorber, R., \& Armstrong, K. J. (1988). The Go-No-Go paradigm in attention deficit disorder. Annals of Neurology, 24(5), 610-614. doi:10.1002/ana.410240504 
INTERPARENTAL CONFLICT, SCLR, AND CHILD'S ATTENTION

Yerkes, R. M., \& Dodson, J. D. (1908). The relation of strength of stimulus to rapidity of habitformation. Journal of Comparative Neurology and Psychology, 18, 459-482. doi:10.1002/cne.920180503 